\title{
Nano-structured Ni-based Active Species Supported on Metallic Substrates as the Efficient Catalysts for Hydrogen Generation from Methane with Water
}

\author{
Linsheng Wang ${ }^{\star 1,2}$ \\ 1. Shokubai Wang Institute, Tokyo 192-0373, Japan \\ 2. National Institute for Materials Science, Tsukuba, Japan
}

*Corresponding Author: Linsheng Wang, E-mail: linsheng_wang@yahoo.com

\begin{abstract}
Nanostructured Ni metal and Ni-Re alloy active species supported on the surface of the total metallic Ni honeycomb substrate and the porous Ni metal substrate are studied as the novel catalyst system for hydrogen generation from steam methane reforming. The bimetallic Ni-Re nano-alloy active species on the surface of the metallic Ni honeycomb substrate or porous Ni metal substrate exhibit the remarkably enhanced activity for steam methane reforming to generate hydrogen especially at lower reaction temperatures. The total metallic catalysts with excellent electric and heat conductivity and almost zero bed pressure loss are expected to be used for the innovation industrial processes.
\end{abstract}

Keywords

Ni-Re nanofiber; Metallic honeycomb; Porous metal substrate; Total metal catalysts; Ni-Re active sites

\section{INTRODUCTION}

Hydrogen is an energy carrier and one of the important feedstocks in the petroleum and chemical industries and semiconductor industry including the processing of fossil fuels and the production of ammonia. Large amount of hydrogen was consumed worldwide every year and the production of hydrogen plays a key role in modern society because there are no natural hydrogen deposits. About $95 \%$ of hydrogen is produced from fossil fuels by steam reforming or partial oxidation of methane and coal gasification with only a small quantity by 
other routes such as biomass gasification or electrolysis of water ${ }^{[1]}$. This process includes high temperatures steam $\left(\mathrm{H}_{2} \mathrm{O}\right)$ reacts with methane $\left(\mathrm{CH}_{4}\right)$ in an endothermic reaction to yield syngas in the first step and additional hydrogen is generated through the lower-temperature exothermic water gas shift reaction in a second step: $\mathrm{CO}+\mathrm{H}_{2} \mathrm{O} \rightarrow \mathrm{CO}_{2}+\mathrm{H}_{2}$

A highly active and sulfur-tolerant bimetallic Ni-Re catalyst system for hydrogen generation from gasoline fuels by steam reforming and oxidative steam reforming has been reported in our previous studies ${ }^{[2-4]}$. The promotional effect of $\mathrm{Re}$ on the activity and stability of $\mathrm{Ni} / \mathrm{Al}_{2} \mathrm{O}_{3}$ catalyst was found for gasoline reforming to produce hydrogen on Ni-Re-based catalysts at lower reaction temperatures with a green process was developed ${ }^{[5-7]}$. The high gasoline conversion of $100 \%$ is maintained very well during $700 \mathrm{~h}$ of operation for steam reforming of desulfurized gasoline feed at lower reaction temperatures. It has been proposed that the high activity and sulfur tolerance of $\mathrm{Ni}-\mathrm{Re} / \mathrm{Al}_{2} \mathrm{O}_{3}$ may be due to the alloying of $\mathrm{Ni}$ with $\mathrm{Re}$ to form the bimetallic Ni-Re alloy nanoparticles. On the other hand, it has been recently reported that $\mathrm{Ni}$ honeycomb exhibited catalytic activity for methane steam reforming (MSR) under low steam-to-carbon ratio and gas hourly space velocity (SV) conditions ${ }^{[8-9]}$. Low pressure drop per catalyst volume and fast heat and mass transport are the evident advantages of the metallic honeycomb catalysts by comparison with conventional pelleted catalysts ${ }^{[10-12]}$. These advantages are desirable for their industrial applications in hydrogen production systems if the activity of the Ni honeycomb catalyst especially at lower temperatures is impoved even under higher SV. In the present presentation, nanostructured Ni and $\mathrm{Ni}-\mathrm{Re}$ active species are fabricated on the surface of the total metallic Ni honeycomb and the porous $\mathrm{Ni}$ metal as the novel catalyst system for hydrogen generation from steam methane reforming.

\section{EXPERIMENTAL}

\subsection{Ni Honeycomb Preparation and Catalytic Reaction}

The pure Ni honeycomb substrate (diameter $6 \mathrm{~mm}$, height $5 \mathrm{~mm}$ ) was assembled by combining $30 \mu \mathrm{m}$ thick flat and wave-shaped pure Ni foils. Ni nanoparticles were supported on the surface of Ni honeycomb substrate to obtain the $\mathrm{Ni} / \mathrm{Ni}$ honeycomb sample by impregnating the Ni honeycomb substrate in aqueous solution of $\mathrm{Ni}\left(\mathrm{NO}_{3}\right)_{2}$ at room temperature, followed by drying and calcination. Ni-Re nanoparticles were supported on $\mathrm{Ni}$ honeycomb substrate and porous $\mathrm{Ni}$ metal substrate to obtain the $\mathrm{Ni}-\mathrm{Re} / \mathrm{Ni}$ honeycomb sample and $\mathrm{Ni}-\mathrm{Re}$ /porous $\mathrm{Ni}$ sample by using the same method as described in the reference ${ }^{[1,2,7]}$. All the samples were reduced by flowing $\mathrm{H}_{2}$ at $553 \mathrm{~K}$ for $2 \mathrm{~h}$ before the catalytic tests. The catalytic tests were carried out in the temperature range of $673-1173 \mathrm{~K}$ at atmospheric pressure for steam reforming of methane in a fixed bed continuous-flow quartz reactor.

\subsection{Catalyst Characterization}

The nanostructured honeycomb catalysts were characterized by XRD, SEM-EDAX etc. The BrunauerEmmett-Teller (BET) specific surface area of the honeycomb before and after the reactions was measured with $\mathrm{Kr}$ adsorption using a surface area analyzer (Micromeritics, ASAP 2020). The surface morphology was analyzed using a scanning electron microscope (SEM; JEOL, JSM-7000F) coupled with an X-ray energy dispersive spectroscopy (EDS) system.

\section{RESULTS}

\subsection{Activity Improvement of Ni Honeycomb by Deposition of Ni Nanoparticles on Its Surface}

The activities of the Ni honeycomb substrate and the Ni honeycomb coated with Ni nanoparticles (Ni/Ni honeycomb) for steam methane reforming at SV of $1200 \mathrm{~h}^{-1}$ and a reaction temperature of $973 \mathrm{~K}$ are compared in Fig 1. 


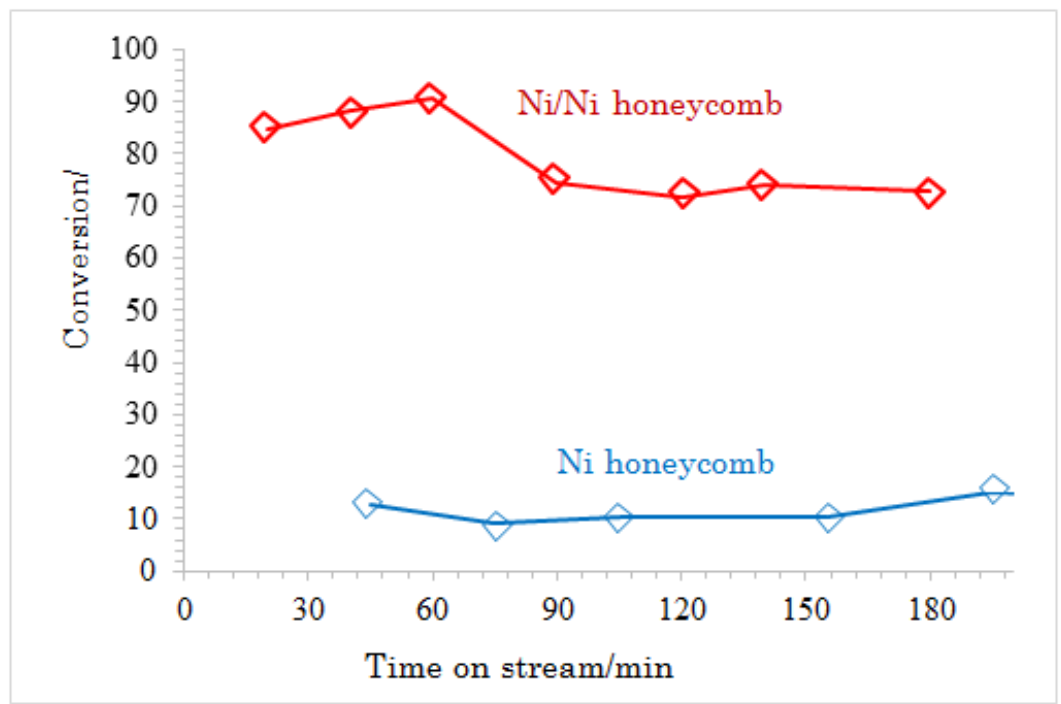

Fig 1 Activity comparison of Ni-honeycomb and Ni-honeycomb supported Ni nanoparticles Reaction conditions: $\mathrm{T}=973 \mathrm{~K} ; \mathrm{SV}=1200 \mathrm{~h}^{-1}$; Mole ratio of $\mathrm{CH}_{4} / \mathrm{H}_{2} \mathrm{O} / \mathrm{N}_{2}=3 / 5 / 1$

We can see from Fig 1 that the conversion of methane on the Ni honeycomb substrate is only about $10 \%$ under the given reaction conditions. However, the conversion of methane on the Ni substrate coated with $\mathrm{Ni}$ nanoparticles (Ni/Ni honeycomb) is more than $80 \%$ under the same reaction conditions. The much higher activity of the Ni/Ni honeycomb than that of the pure Ni honeycomb substrate is contributed to the Ni nanoparticles coated on the Ni honeycomb substrate. Therefor coating of Ni nanoparticles on the surface of Ni honeycomb substrate is effective to improve the catalytic activity of the pure Ni honeycomb catalyst at lower reaction temperature and higher SV. Therefore the activity of the Ni honeycomb catalysts can be remarkably enhanced by depositing the $\mathrm{Ni}$ nanoparticles on the surface of the honeycomb $\mathrm{Ni}$. The methane conversion on the $\mathrm{Ni} / \mathrm{Ni}$-honeycomb at the reaction temperature of $973 \mathrm{~K}$ and SV of $1200 \mathrm{~h}^{-1}$ and the mole ratio of $\mathrm{CH}_{4} / \mathrm{H}_{2} \mathrm{O} / \mathrm{N}_{2}$ of $3 / 5 / 1$ is about $80 \%$, which is about 5 time higher than that on the Ni honeycomb substrate.

Fig 2 shows the XRD patterns of the Ni honeycomb substrate and the Ni honeycomb deposited with Ni nanoparticles on the surface.

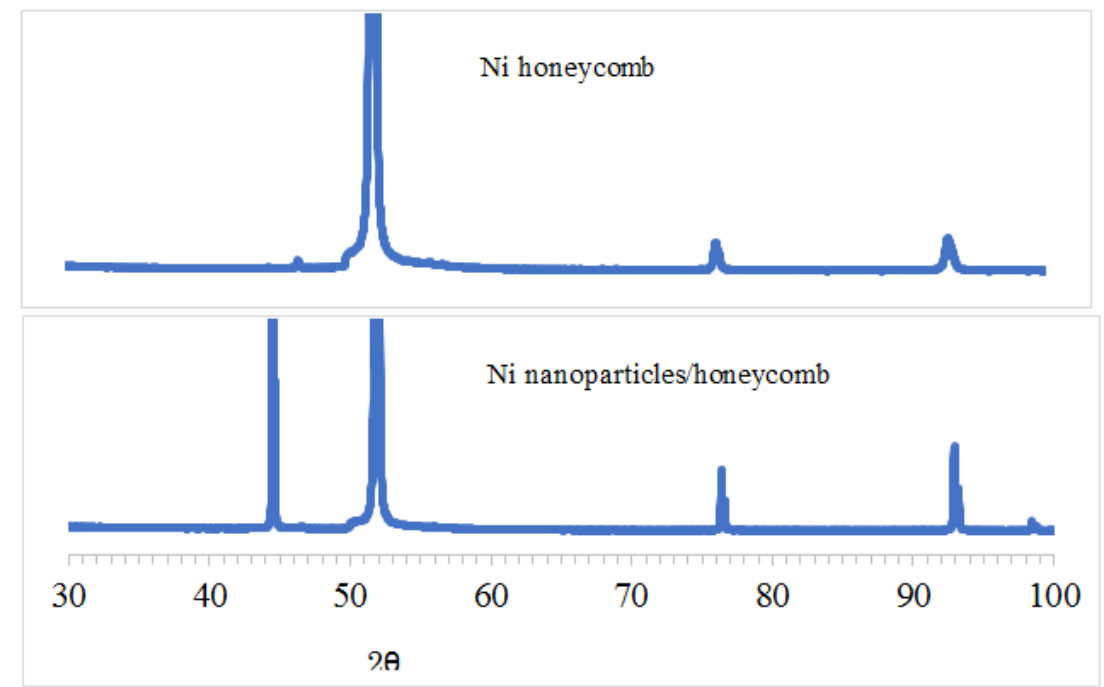

Fig 2. XRD patterns of the Ni nanoparticles supported on the honeycomb Ni 
It is clear in Fig 2 that 3 XRD peaks of the peak at the 2 theta angel of 52 degree, the Ni (220) peak at the 2 theta angel of 77 degree and the $\mathrm{Ni}$ (311) peak at the 2 theta angel of 93 degree are appeared on the $\mathrm{Ni}$ honeycomb substrate. The $\mathrm{Ni}$ (111) peak at the 2 theta angel of 44.5 degree is also appeared after Ni nanoparticles is deposited on the surface of the honeycomb $\mathrm{Ni}$, which is not appeared on the Ni honeycomb substrate. Therefore, the Ni (111) peak at the 2 theta angel of about 44.5 degree is assigned to the Ni nanoparticles supported on the Ni honeycomb substrate. The increased activity of $\mathrm{Ni} /$ honeycomb $\mathrm{Ni}$ is ascribed to the high activity of the Ni nanoparticle on the surface of the Ni honeycomb.

\subsection{Effect of alloying of Ni with Re to form Ni-Re alloy nanoparticles on the surface of Ni honeycomb}

Fig 3 shows the conversions for steam methane reforming on and $\mathrm{Ni}-\mathrm{Re} / \mathrm{Ni}$ honeycomb catalysts at different reaction temperatures and a $\mathrm{SV}$ of $1200 \mathrm{~h}^{-1}$ and mole ratio of $\mathrm{CH}_{4} / \mathrm{H}_{2} \mathrm{O} / \mathrm{N}_{2}$ of $3 / 5 / 1$.

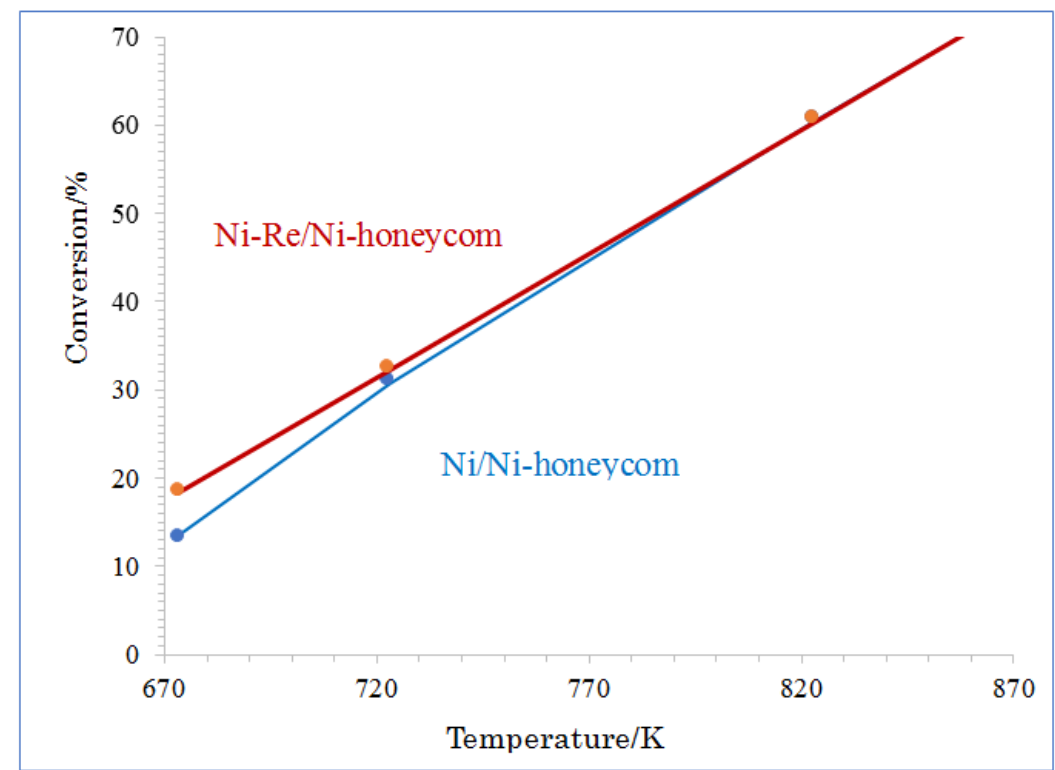

Fig 3 Low temperature activity enhancement by alloying of Ni with Re on the surface of honeycomb Ni at $\mathrm{SV}$ of $1200 \mathrm{~h}^{-1}$ and $\mathrm{CH}_{4} / \mathrm{H}_{2} \mathrm{O} / \mathrm{N}_{2}$ mole ratio of $3 / 5 / 1$

We can see from Fig 3 that the activity of Ni-Re/Ni-honeycomb catalyst is evidently higher than that of Ni/ $\mathrm{Ni}$ honeycomb catalyst at the lower reaction temperatures of $673 \mathrm{~K}$ and $723 \mathrm{~K}$. This indicates that the bimetallic $\mathrm{Ni}-\mathrm{Re}$ alloy nanoparticles formed by alloying of $\mathrm{Ni}$ with $\mathrm{Re}$ is more active that the monometallic Ni nanoparticles supported on the surface of Ni honeycomb Ni substrate for steam methane reforming to generate hydrogen. The activities of the two catalysts become close with increasing reaction temperature as shown in Fig 3 . This indicates that the steam methane reforming reaction becomes thermochemical equilibrium with increasing the reaction temperature.

Table 1 compares the activity of Ni-Re nanoparticles/Ni honeycomb and Ni nanoparticles/Ni honeycomb for steam methane reforming at a low reaction temperature of $723 \mathrm{~K}$ and the high SV of $4000 \mathrm{~h}^{-1}$ and $7200 \mathrm{~h}^{-1}$.

Table 1 Effect of surface alloying with rhenium on the activity for steam methane reforming reaction at a lower reaction temperature

\begin{tabular}{|c|c|c|c|}
\hline Catalyst & $\mathrm{SV}\left(\mathrm{h}^{-1}\right)$ & Conversion $(\%)$ & $\mathrm{CO} /\left(\mathrm{CO}+\mathrm{CO}_{2}\right)(\%)$ \\
\hline \multirow{2}{*}{$\mathrm{Ni}(10 \mathrm{wt} \%)$} & 5000 & 1.5 & 12.8 \\
\cline { 2 - 4 } & 9000 & 0.3 & 90 \\
\hline
\end{tabular}


续表:

\begin{tabular}{|c|c|c|c|}
\hline Catalyst & $\mathrm{SV}\left(\mathrm{h}^{-1}\right)$ & Conversion $(\%)$ & $\mathrm{CO} /\left(\mathrm{CO}+\mathrm{CO}_{2}\right)(\%)$ \\
\hline \multirow{2}{*}{$\mathrm{Ni}(10 \mathrm{wt} \%) \operatorname{Re}(1 \mathrm{wt} \%)$} & 5000 & 22.5 & 6.5 \\
\cline { 2 - 4 } & 9000 & 15.5 & 6.5 \\
\hline \multirow{2}{*}{$\mathrm{Ni}(5 \mathrm{wt} \%)$} & 7200 & 16.0 & 0.8 \\
\cline { 2 - 4 } & 4000 & 20.2 & 0 \\
\hline \multirow{2}{*}{$\mathrm{Ni}(5 \%) \operatorname{Re}(0.5 \mathrm{wt} \%)$} & 7200 & 21.3 & 11.5 \\
\hline \multirow{2}{*}{$\mathrm{Ni}(2.5 \mathrm{wt} \%)$} & 4000 & 2.1 & 2.6 \\
\cline { 2 - 4 } & 7200 & 6.4 & 11.5 \\
\hline \multirow{2}{*}{$\mathrm{Ni}(2.5 \%) \operatorname{Re}(0.25 \mathrm{wt} \%)$} & 4000 & 2.1 & 1.0 \\
\cline { 2 - 4 } & 7200 & 17.1 & 0 \\
\hline
\end{tabular}

Pretreat conditions: Reduction by $\mathrm{H}_{2}$ at $703 \mathrm{~K}$ for $1 \mathrm{~h}$; Reaction conditions: React. Temp. $=723 \mathrm{~K}$

We can see from Table 1 that the activity enhancement of the Ni/Ni honeycomb catalyst for steam methane reforming by surface alloying of $\mathrm{Ni}$ with $\mathrm{Re}$ to form Ni-Re alloy nanoparticles become more remarkably at the increasing space velocity (SV). The methane conversion on $\mathrm{Ni}(2.5 \mathrm{wt} . \%)$-Re $(0.25 \mathrm{wt} . \%) /$ $\mathrm{Ni}$ honeycomb catalyst is about 2 times higher than that on $\mathrm{Ni}(2.5 \mathrm{wt} . \%) / \mathrm{Ni}$ honeycomb catalyst at a $\mathrm{SV}$ of $4000 \mathrm{~h}^{-1}$ and the methane conversion on $\mathrm{Ni}(2.5 \mathrm{wt} . \%)$ - Re $(0.25 \mathrm{wt} . \%) / \mathrm{Ni}$ honeycomb catalyst is about 7 times higher than that on $\mathrm{Ni}(2.5 \mathrm{wt} . \%) / \mathrm{Ni}$ honeycomb catalyst at a SV of $7200 \mathrm{~h}^{-1}$ as shown in Table 1. We also can see the comparison between the activity of Ni ( $5 \mathrm{wt} . \%)$ - Re $(0.5 \mathrm{wt} . \%) / \mathrm{Ni}$ honeycomb and $\mathrm{Ni}(5 \mathrm{wt} . \%) / \mathrm{Ni}$ honeycomb for steam methane reforming at a low reaction temperature of $723 \mathrm{~K}$ and high $\mathrm{SV}$ of $4000 \mathrm{~h}^{-1}$ and $7200 \mathrm{~h}^{-1}$ in Table 1 . It is shown in Table 1 that the activity enhancement of the Ni/Ni honeycomb catalyst for steam methane reforming by surface alloying of $\mathrm{Ni}$ with $\mathrm{Re}$ to form $\mathrm{Ni}-\mathrm{Re}$ alloy nanoparticles become more evidently at the increasing space velocity (SV). The methane conversion on $\mathrm{Ni}(5 \mathrm{wt} . \%)$ - Re $(0.5 \mathrm{wt} . \%) / \mathrm{Ni}$ honeycomb catalyst and $\mathrm{Ni}(5 \mathrm{wt} . \%) / \mathrm{Ni}$ honeycomb catalysts is about $22 \%$ and $18 \%$ respectively at a SV of $4000 \mathrm{~h}^{-1}$ and the methane conversion on Ni (5wt.\%)-Re (0.5wt.\%)/ $\mathrm{Ni}$ honeycomb catalyst and $\mathrm{Ni}(5 \mathrm{wt} . \%) / \mathrm{Ni}$ honeycomb catalysts is about $22 \%$ and $16 \%$ respectively at a higher SV of $7200 \mathrm{~h}^{-1}$ as shown in Table 1 . The $\mathrm{CO}_{2}$ selectivity on $\mathrm{Ni} / \mathrm{Ni}$ honeycomb catalysts is higher than that on Ni-Re/Ni honeycomb catalysts. The activity of Ni (5wt.\%)-Re (5wt.\%)/Ni honeycomb, Ni (5wt.\%)-Re (10wt.\%)/Ni honeycomb and $\mathrm{Ni}(5 \mathrm{wt} . \%) / \mathrm{Ni}$ honeycomb catalysts for steam methane reforming at different reaction temperatures and a high SV of 20000h-1 are studied. The activity of Ni (5wt.\%)Re (5wt.\%)/Ni honeycomb and Ni (5wt.\%)-Re (10wt.\%)/Ni are much higher than that of the Ni/Ni honeycomb catalyst for steam methane reforming at the high space velocity (SV) of $20000 \mathrm{~h}^{-1}$ and a wide range of reaction temperatures. However, the activity of $\mathrm{Ni}(5 \mathrm{wt} . \%)-\mathrm{Re}(10 \mathrm{wt} . \%) / \mathrm{Ni}$ honeycomb is a little higher than that of $\mathrm{Ni}(5 \mathrm{wt} . \%)-\mathrm{Re}(5 \mathrm{wt} . \%) / \mathrm{Ni}$ honeycomb. We also use porous $\mathrm{Ni}$ with average pore size of $450 \mu \mathrm{m}$ as substrate to prepare the $\mathrm{Ni}(10 \mathrm{wt} \%) /$ porous-Ni and $\mathrm{Ni}(10 \mathrm{wt} \%)-\operatorname{Re}(1 \mathrm{wt} \%) /$ porous-Ni catalysts for steam methane reforming. The activities of the $\mathrm{Ni}(10 \mathrm{wt} \%) /$ porous $\mathrm{Ni}$ and $\mathrm{Ni}(10 \mathrm{wt} \%)-\mathrm{Re}(1 \mathrm{wt} \%) /$ porous $\mathrm{Ni}$ catalysts for steam methane reforming at a wide range of reaction temperature from $673 \mathrm{~K}$ to $1173 \mathrm{~K}$ are compared in Fig 4. We can see from Fig 4 that the Ni(10wt\%)-Re(1wt\%)/porous Ni catalyst exhibits the evident activity at $673 \mathrm{~K}$ and methane conversion increases with increasing reaction temperature from $673 \mathrm{~K}$ to $1173 \mathrm{~K}$. However, the starting reaction temperature for catalyzing steam methane reforming on $\mathrm{Ni}(10 \mathrm{wt} \%)$ /porous $\mathrm{Ni}$ is about $1023 \mathrm{~K}$. Therefor the activity $\mathrm{Ni}$ /porous $\mathrm{Ni}$ for steam methane reforming is remarkably enhanced by surface alloying of $\mathrm{Ni}$ with $\mathrm{Re}$ to form $\mathrm{Ni}$-Re alloy nanoparticles on the porous Ni substrate as shown in Fig 4. 


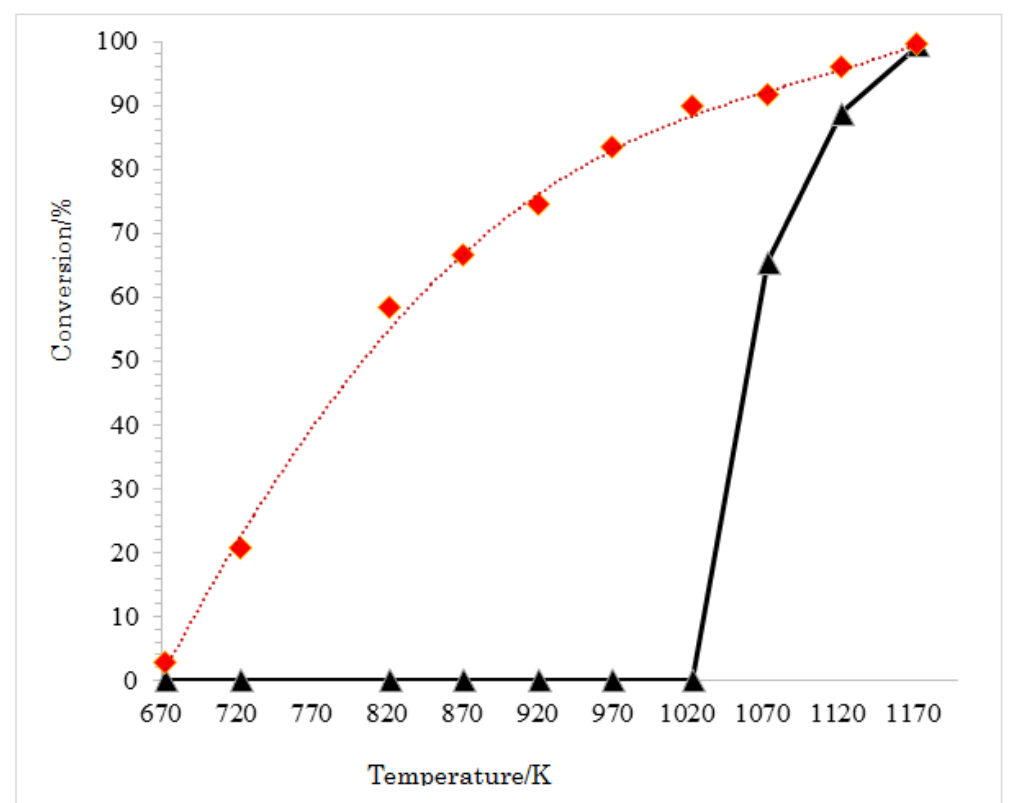

Fig 4. Activity comparison of the $\mathrm{Ni}(10 \mathrm{wt} \%) /$ porous $\mathrm{Ni}$ and $\mathrm{Ni}(10 \mathrm{wt} \%) \mathrm{Re}(1 \mathrm{wt} \%) /$ porous $\mathrm{Ni}$ catalysts for steam methane reforming at a wide range of reaction temperature from $673-1173 \mathrm{~K}$ with $\mathrm{CH}_{4} / \mathrm{H}_{2} \mathrm{O} / \mathrm{N}_{2}$ mole ratio of $3 / 5 / 9$ and $S V$ of $6580 h^{-1}$

The structures of the bimetallic Ni-Re alloy nanoparticles and the monometallic Ni nanoparticles are examined by XRD. Fig 5 shows the XRD patterns of Ni (5wt.\%)-Re (2wt.\%)/Ni honeycomb, Ni (5wt.\%)Re (1wt.\%)/Ni honeycomb, Ni (5wt.\%)-Re (0.5wt.\%)/Ni honeycomb and Ni (5wt.\%)/Ni honeycomb samples. We can see from Fig 5 that the Ni (111) peak at 2theta angel of 44.5 degree become wider after alloying of Ni nanoparticles with Re to form Ni-Re alloy nanoparticles. This indicates that the surface alloying of $\mathrm{Ni}$ with $\mathrm{Re}$ improving the dispersion of the Ni nanoparticles on the Ni honeycomb. In order to observe the change of Ni (111) peak more clearly after surface alloying of $\mathrm{Ni}$ with $\mathrm{Re}$, we enlarge the XRD patterns from 2 theta angel range from 40 to 50 degree as shown in Fig 5. XRD patterns of Ni (5wt.\%)-Re (2wt.\%)/Ni honeycomb, Ni (5wt.\%)-Re (1wt.\%)/ $\mathrm{Ni}$ honeycomb, $\mathrm{Ni}(5 \mathrm{wt} . \%)-\mathrm{Re}(0.5 \mathrm{wt} . \%) / \mathrm{Ni}$ honeycomb and $\mathrm{Ni}(5 \mathrm{wt} . \%) / \mathrm{Ni}$ honeycomb samples is enlarged at the 2theta angel of 40-50 and 75.5-77 in Fig 5.
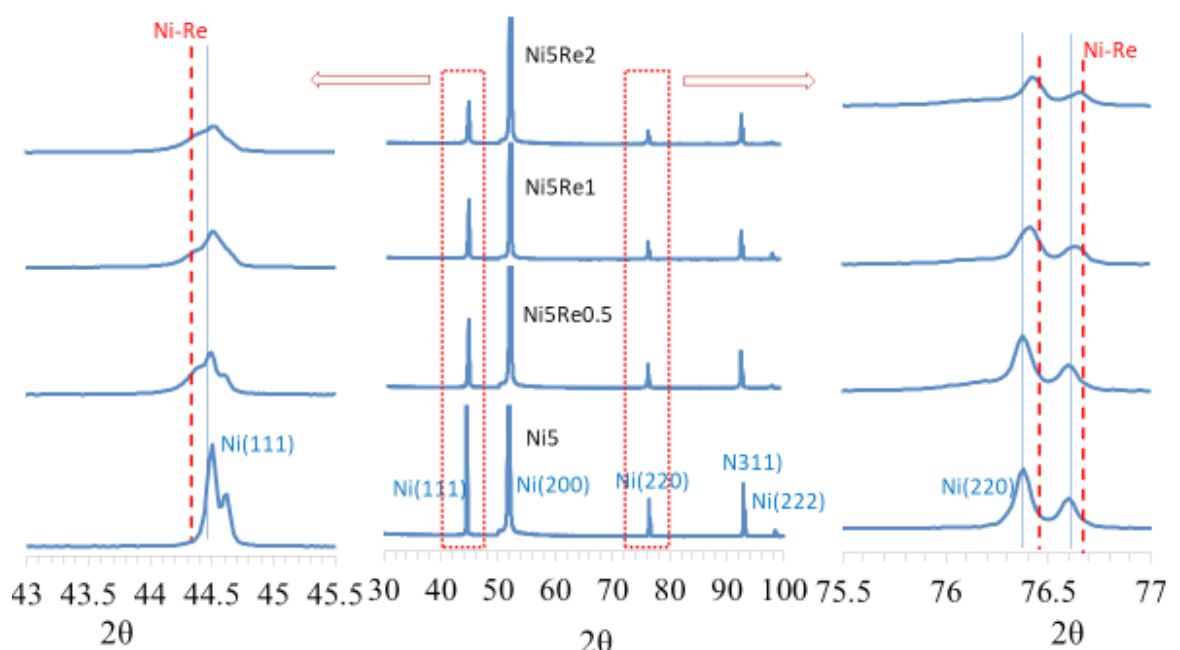

Fig 5 XRD patterns of Ni (5wt.\%)-Re (2wt.\%)/Ni honeycomb, Ni (5wt.\%)-Re (1wt.\%)/Ni honeycomb, Ni (5wt.\%)-Re (0.5wt.\%)/Ni honeycomb and Ni (5wt.\%)/Ni honeycomb samples. 
We can clearly see from Fig 5 that a new peak near the Ni (111) peak is appeared on Ni-Re/Ni honeycomb samples. However, this new peak is not appeared on Ni/Ni honeycomb sample. Therefor this new XRD peak is assigned to the Ni-Re alloy nanoparticles formed by surface alloying of $\mathrm{Ni}$ with $\mathrm{Re}$. The monometallic Ni nanoparticles are synthesized by reduction of their oxide precursors of $\mathrm{NiO}$ and the bimetallic Ni-Re alloy nanoparticles are synthesized by their precursors of $\mathrm{NiO} \cdot \mathrm{ReO}_{\mathrm{x}}$. The precursors of the bimetallic Ni-Re alloy nanoparticles and the monometallic Ni nanoparticles are observed by SEM and their images are shown in Fig 6 .

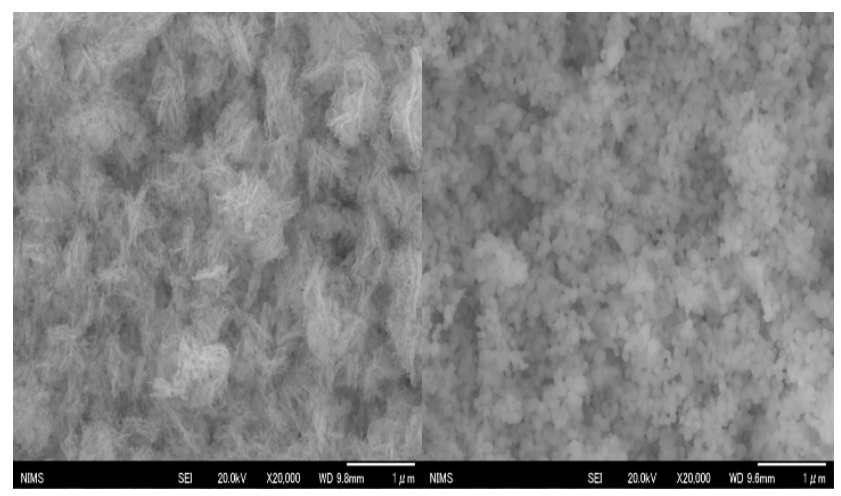

Fig 6 SEM images of precursors for synthesis of the bimetallic Ni-Re alloy nanoparticles and the monometallic Ni nanoparticles on Ni honeycomb substrate

We can find from Fig 6 that the SEM images of the precursors for bimetallic Ni-Re alloy nanoparticles are look quite different from the SEM images of the precursors for monometallic Ni nanoparticles. The SEM images of the precursors for bimetallic Ni-Re alloy nanoparticles look like the nanofibers. The SEM images of the precursors for monometallic Ni nanoparticles are nanoparticles.

\section{CONCLUSION}

Two types of total metallic catalysts of Ni honeycomb and porous Ni which are deposited with bimetallic $\mathrm{Ni}-\mathrm{Re}$ alloy nanoparticles with excellent electric and heat conductivity and almost zero bed pressure loss are successfully fabricated. The surface alloying effect of Ni with Re lead to the appearing of new XRD peak which is assigned to the synthesized bimetallic Ni-Re nanoparticles. The bimetallic Ni-Re alloy nanoparticles deposited on $\mathrm{Ni}$ honeycomb substrate or porous $\mathrm{Ni}$ substrate exhibit the remarkably enhanced activity for steam methane reforming to generate hydrogen especially at lower reaction temperatures by comparison with the monometallic Ni nanoparticles deposited on the Ni honeycomb substrate or porous Ni substrate.

\section{REFERENCES}

[1] Ogden, J.M. Prospects for building a hydrogen energy infrastructure. Annual Review of Energy and the Environment. 1999, 24: 227-279. doi:10.1146/annurev.energy.24.1.227.

[2] Wang,L, Murata,K, Inaba M, Development of Novel Highly Active and Sulphur-Tolerant Catalysts for Steam Reforming of Liquid Hydrocarbons to Produce Hydrogen, Applied Catalysis A: General, 2004, 257, $43-47$.

[3] Wang L, Murata K, Inaba M, Appl. Catal. B: Environ. Control of the product ratio of $\mathrm{CO}_{2} /\left(\mathrm{CO}+\mathrm{CO}_{2}\right)$ and inhibition of catalyst deactivation for steam reforming of gasoline to produce hydrogen", Applied Catalysis B: Environmental, 2004, 48, 243-248.

[4] Wang L, Murata K, Inaba M, Conversion of liquid hydrocarbons into $\mathrm{H}_{2}$ and $\mathrm{CO}_{2}$ by integration of reforming and water-gas shift reaction on highly active multifunctional catalysts", Industrial \& Engineering Chemistry Research, 2004, 43, 3228-3232.

[5] Wang L, Murata K, Inaba M, "Steam reforming of gasoline promoted by partial oxidation reaction on novel 
bimetallic Ni-based catalysts to generate hydrogen for fuel cells powered automobile applications", Journal of Power Sources, 2005, 145, 707-7112005.

[6] Wang L, Murata K, Matsumura Y, Inaba M, Lower-temperature catalytic performance of bimetallic Ni-Re/ $\mathrm{Al}_{2} \mathrm{O}_{3}$ catalyst for gasoline reforming to produce hydrogen with inhibiting formation of methane", Energy \& Fuels, 2006, 20, 1377-1381.

[7] Wang L, Murata $\mathrm{K}$, Inaba $\mathrm{M}$, Highly efficient conversion of gasoline into hydrogen on $\mathrm{Al}_{2} \mathrm{O}_{3}$-supported Nibased catalysts: catalyst stability enhancement by modification with W", Applied Catalysis A: General, 2009, 358, 264-268.

[8] Fukuhara C, Yamamoto K, Makiyama Y, Kawasaki W, Watanabe R, A metal honeycomb-type structured catalyst for steam reforming of methane: effect of preparation condition change on reforming performance, Appl. Catal. A: Gen. 2015, 492, 190-200

[9] Hiramitsu Y, Demura M, Xu Y, Yoshida M, Hirano T, Catalytic properties of pure Ni honeycomb catalysts for methane steam reforming, Appl. Catal. A: Gen. 2015, 507, 162-168.

[10] Flytzani-Stephanopoulos M, Voecks G E, Charng T, Modeling of heat-transfer in nonadiabatic monolith reactors and experimental comparisons of metal monoliths with packed-beds, Chem. Eng. Sci. 1986, 41, $1203-1212$.

[11] Farrauto R J, Liu Y, Ruettinger W, Ilinich O, Shore L, Giroux T, Precious metal catalysts supported on ceramic and metal monolithic structures for the hydrogen economy, Catal. Rev. 2007, 49, 141-196.

[12] Xu Y, Harimoto T, Wang L, Hirano T, Kunieda H, Hara Y, Miyata Y, E, ect of steam and hydrogen treatments on the catalytic activity of pure Ni honeycomb for methane steam reforming, Chemical Engineering \& Processing: Process Intensification, 2018, 129, 63-70 